\title{
Consuming Wellbeing and Happiness through Epicurean Ingestion
}

\begin{tabular}{|r|l|}
\hline Journal: & Qualitative Market Research \\
\hline Manuscript ID & QMR-06-2018-0061.R2 \\
\hline Manuscript Type: & Research Paper \\
\hline Keywords: & $\begin{array}{l}\text { Food Consumption, Pleasure, Taste, Happiness, Food Well-Being, } \\
\text { Experiential consumption }\end{array}$ \\
\hline \multicolumn{2}{|l}{} \\
\hline
\end{tabular}

\section{SCHOLARONE" \\ Manuscripts}




\begin{abstract}
Purpose - This paper investigates the idea of eating for pleasure and its effect on consumer wellbeing. It will begin by introducing the concept of Food Well-Being (FWB) under the Transformative Consumer Research (TCR) agenda. Subsequently, it will provide detailed discussions on the concept of pleasure, under which, food practices involving epicurean pleasure, hedonic and eudaimonic consumption will be discussed.

Design/methodology/approach - This paper then takes a different approach to the usual qualitative methodologies by utilising an introspective analysis of the film- 'Eat, Pray, Love' where the consumption of food for pleasure was heavily practiced.

Findings - This paper presents the introspective voice of the lead author's food consumption. It reveals a food consumption practice which followed an initial loss of taste, to alternative food consumption and finally slow food ingestion. The journey of her epicurean ingestion revealed pleasurable experiences that reflected a positive subjective well-being. This attitude of ingesting food and living for the moment, propelled the idea that food wellbeing is more about consumer happiness.

Originality - This paper is novel in its approach to utilise film introspection to probe the concept of FWB within TCR. Additionally, it reveals the transitioning moment of alternative food consumption that leads to pleasurable experience. It also reveals that a personal investment in cooking for self, restores taste and improves subjective well-being. Overall, it showcases how the appreciation of the sensations of food from its taste, as it was ingested gradually leads to the total experiential feeling embedded in food consumption.
\end{abstract}

Keywords - Food Consumption, Pleasure, Taste, Happiness, Food Well-Being, Experiential consumption Paper Type - Research Paper

\title{
1. Introduction
}

Mick (2006) introduced Transformative Consumer Research (TCR) in marketing to tackle consumer wellbeing issues, equivalent to the French research 'bien-être du consommateur' where wellbeing is associated with feelings of pleasure (Gorge et al., 2015). Such pleasures encompass the subjective nature of happiness encapsulated in the Subjective Well-Being (SWB) construct (Guven and Sørensen, 2012) alongside, presence/absence of positive/negative mood and life satisfaction (Ryan and Deci, 2001). SWB rooted within hedonic psychology, measures the affective and cognitive evaluations of positive versus negative effects experienced during a person's life (Diener, 2000; Zhong and Mitchell, 2012). Positive perception for instance, of social class and income leads to SWB that drives consumption desire (Guven and Sørensen, 2012). The food consumption aspect in TCR began following Block et al. (2011, p. 6) Food Well-Being (FWB) construct, as the "positive psychological, physical, emotional and social relationship with food at both the individual and societal levels". This concept was developed 
to connect marketing with fields concerned with health, food and nutrition (Ozanne, 2011). This was later advanced by Bublitz et al. (2011) who sought to shift focus from 'Food as Heath' to 'Food as Well-Being'. Hence, the concept was perceived as a continuum covering five areas that prevented consumers from attaining wellbeing namely; social influences, economic factors, food literacy, emotional knowledge and self-re-evaluation (Bublitz et al., 2013). Yet, while this concept is concerned with the interrelationship among pleasurable food experiences, overall health and well-being, (Bublitz et al., 2013) the areas covered were just factors that affect healthy food decision making. While for some consumers, food is essential for survival, others perceive food as love which generates a source of pleasure (Bublitz et al., 2011).

Still, despite the shift to consider food as wellbeing instead of food as health, insights have only focused on challenges to health, that is, factors previously neglected surrounding food that may prevent consumers from attaining good health. Nevertheless, Cornil and Chandon (2015) drew on the fact that the continuous emphasis placed on self-control can reduce eating enjoyment and food wellbeing, though this was analysed through a quantitative approach. Therefore, the aim of this paper is analyse how a consumer's subjective wellbeing can be derived from food consumption. The research question then is what pleasurable experiences can be associated with food that contributes to a consumer's subjective wellbeing? Hence, this paper adopts an introspective approach to expose more experiential and affective aspects of food consumption.

\section{Literature review \\ 2.1 Pleasure from food}

The pleasure of eating is a peculiar sensation experienced from the satisfaction of hunger (Cornil and Chandon, 2015, p. 53). Food is a source of pleasure which provides physical and emotional satisfaction (Madichie, 2007). Satisfaction is attained when an individual experiences satiety while eating, which brings the eating process at that moment to a halt (Cornil, 2017). Hence, the pleasure of food increases when one is hungry and decreases upon satisfaction (Cornil and Chandon, 2015). While pleasure is inherent in food, consumer researchers have also recognised the importance of happiness (Alba and Williams, 2013). Aristotle perceived happiness as the highest good and an indication that one's life is going well (O'Keefe, 2014). To him, happiness is a 'vulgar ideal' driving people to mindlessly follow their desires (Ryan and Deci, 2001). This was reiterated by de Sade and supported by Hobbes who believed that happiness is the successful pursuit of human appetite (Ryan and Deci, 2001). However, health concerns have probed a negative feeling in people towards eating for pleasure, especially indulging in comfort food. Comfort foods provides a consolidated feeling of wellbeing which when consumed, elevate loneliness and enhances moods due to the opiates it contains (Spence, 2017) that transforms a person to a pleasurable state (Wansink et al., 2003).

Pleasures from food, can be of visceral or epicurean form. Visceral pleasure can occur when an individual experiences negative emotions that spikes eating impulses leading to overeating and generates a short-lived pleasure (Cornil and Chandon, 2015). However, epicurean eating pleasure is derived when a person appreciates the sensory and symbolic value of food, (Cornil and Chandon, 2015) takes delight in food consumption and finds it pleasurable (O’Keefe, 2014). For the Greek Philosopher Epicurus, when a person's life purpose is directed by pleasure they will 
ultimately be happy (Annas, 1987). The modern day Epicureanism involves the appreciation of food and drink reflected in the pleasure of gastronomy and culinary cultures (Cornil and Chandon, 2015). This is shown in the idea of 'eating out' an activity widespread among social groups, characterised by multi-sensory sensations of flavours, visual images and experiences during food consumption (Rezende and Silva, 2014). Eating-out was even tagged an integral part of everyday life (Madichie, 2007) which has surpassed its aim for utilitarian value, such as saving time and energy to becoming an occasion itself for pleasure, distraction and satisfaction (Kalita and Sarma, 2017). However, such eating out behaviour is determined by the consumer's taste "a gastronomy sense that makes humans capable of differentiating the flavours that constitute a food or drink' (Maret and Geyzen, 2015, p. 1).

Sociologists have been concerned with the differences in the social determination of taste among classes in society (Maret and Geyzen, 2015). This is situated in Bourdieu's classification of the human cultural capital which encompasses taste, experiences and world views (Hoyer and Stokburger-Sauer, 2012). As a French philosopher, Bourdieu perceived this form of epicurean eating pleasure to be acquired by people with higher cultural capital who have learned to appreciate the French haute cuisine (Cornil and Chandon, 2015). This cultural capital is mostly expressed by the elites through their aesthetic and exquisite style (Bourdieu, 1984; Holt, 1997). Additionally, eating rituals such as mindful eating which involves paying attention to the sensory and emotional responses when eating; for instance, the sensations that arise from unwrapping a chocolate bar is an epicurean pleasure (Cornil and Chandon, 2015). This is similar to the mindfulness meditation approach offered by Thich Nhat Hanh of an orange where the individual appreciates the sensory appeals of peeling it, absorbing its smell, to eating it (Kaza, 2008). This shows that to some degree that mindfulness, particularly, an introspective awareness has effect on savouring food (Bryant and Veroff, 2007). Generally, this part of consumption that involves taste and aesthetics is hedonic consumption (Hoyer and Stokburger-Sauer, 2012).

\subsection{Hedonic consumption}

Hedonic consumption was introduced in consumer research by Hirschman \& Holbrook (1982) as the multisensory, fantasy and emotive aspects of ones' experience with products. Hedonism is the natural lens through which we examine the consumption experiences of people who exhibit a positive attitude towards pleasure (Titz, 2008). Thus, hedonic consumption is 'person driven' and consumed products serves as a means to attain a pleasurable end (Alba and Williams, 2013). Hedonic consumption involves emotional and affective experiences of pleasure, fun and fantasy (Kronrod et al., 2012; Zhong and Mitchell, 2010). Emotions particularly, the positive ones are essential for wellbeing (Fredrickson, 2001). Food and drinks are among the top sources that leads to the experience of hedonism (Bryant and Veroff, 2007; Titz, 2008). This consumption experience involves three emotions; feelings, fun and fantasy, where the fun element is the experience derived from aesthetic enjoyment (Holbrook, 2006). The regular consumption of hedonic products characterised by the affective and sensory experience of aesthetics leads to greater wellbeing (Zhong and Mitchell, 2010, 2012). Such aesthetic response to food is expressed by communicating the visual, auditory and sensory modes perceived as exemplified in a respondent reply from a mass observation study "good wine can make me feel orgasmic. The nose, taste and glow one gets can be overwhelming" (Bryant and Veroff, 2007, p. 7). 
However, some consumers believe the positive feelings attributed consuming hedonic products decreases after repeated usage, a phenomenon referred to as the hedonic treadmill of consumption (Cornil, 2017). It is anticipated that most consumers labour on the hedonic treadmill (Diener, 2000), a pessimist idea that happiness is only temporary (Lyubomksky et al., 2005), thus nothing in this case, 'happiness' lasts forever. Still, from Aristippus philosophy, happiness is believed to be the totality of one's hedonic moments (Ryan and Deci, 2001). Epicurus was also tagged a hedonist who believed people's final end should be eudaimonic or happiness (Annas, 1987). Hence, most consumers in developed countries perceive happiness as the goal of consumption (Lee and Ahn., 2016), as happiness has been identified to improve wellbeing and psychological health (Gruber et al., 2011). Currently, there are two traditional approaches to wellbeing. The hedonic approach, where wellbeing is defined by an attainment of happiness and the eudaimonic approach, where wellbeing is the ability of a person to function fully, focusing on meaning and self-realization (Ryan and Deci, 2001). The eudaimonic approach is an aspect of Self-Determination Theory (SDT) which believes that the fulfilment of an individual's intrinsic and psychological needs, leads to wellbeing and self-actualisation (Dittmar, 2007; Ryan and Deci, 2001). The hedonic aspects involving happiness leads to positive emotions and the absence of negative emotions (Gruber et al., 2011).

However, although Eudaimonia has been described as an approach that leads to hedonic enjoyment, the same is not true of the reverse (Deci and Ryan, 2008). Explanations for this idea can be derived from Hellenic philosophy (Waterman, 1993) specifically, Aristotle's stance on happiness postulated in Nicomachean Ethic (Ryan et al., 2008). In Nicomachean Ethic, the highest good is Eudaimonia (Ryff, 1989; Ryff and Singer, 2008), derived from ‘eu daimon' meaning good demon, such that, only a person who has a 'good demon' or fortune, will attain happiness (Bruni, 2010) and beckons people to recognise their 'daimon' or true self (Waterman, 1993). Hence, it is a more enduring sort of happiness that involves pleasure but also comprises effective meaningfulness and growth (Bauer et al., 2008). For Aristotle, happiness is the indirect result of practising good virtues- a basic tenet tagged the fundamental paradox of egoistic hedonism (Bruni, 2010). Such virtues involves living with reason and moderation, eudaimonia is not a feeling but a description of character (Ryan et al., 2008). It has further been suggested that mindfulness characterises people engaged in an eudaimonic life (Ryan et al., 2008). This is not surprising considering mindfulness has also been linked to SDT explaining how an open awareness will be beneficial towards alignment of behavioural choice with ones needs (Brown and Ryan, 2003). Still, unsatisfied that SWB which is related to the Aristotelian approach to happiness (Bruni, 2010) does not fully define wellbeing, Ryff \& Singer (2008) introduced Psychological Well-Being (PWB) aiming at individual self-development and self-realization. PWB is composed of self-acceptance, personal growth, relatedness, autonomy, relationships, environmental mastery and purpose in life (Deci and Ryan, 2008).

Due to the perceived enjoyment and pleasure that one can derive from food which can lead to hedonic consumption, the glaring importance of eudaimonia- a superior form of happiness coupled with researchers focus to consider not just SWB but also PWB; this paper will explore such experiential aspects of food consumption. It has chosen to perform a film analysis to understand the certain elements involved in the pleasure of food consumption. 


\section{Methodology}

\subsection{Introspection as a research method}

This paper applies Introspection as a research method to analyse a film. Introspection was chosen because it represents a phenomenological experience which provides access to a consumer's ongoing lived experience. This hence, reduces limitations concerning invading the informant's privacy as in interviews and other qualitative methodologies (Batat and Wohlfeil, 2009; Wohlfeil and Whelan, 2008). It is a transformative research method (Custer, 2014), that enables the researcher to explore the subjective nature of human feelings inaccessible by other methods (Wohlfeil and Whelan, 2011) and produces evoking thick descriptions of experiences (Ellis et al., 2011). The application of Introspection in Consumer Research was popularised by Gould (1991) who introspected on his pervasive consumption of energy. Subsequently, Holbrook (1997) addressed introspection as Subjective Personal Introspection (SPI) and utilised it to study the romantic aspects of consumption. He even refers to himself as 'Morris the epicurean' and draws from Campbell and Montague's essays, emphasising a consumption experience continuum where romanticism leads to experiential consumption, emotional responses and ultimately pleasure. From Montague's essays Holbrook concludes "I write about myself, I inevitably describe some aspect of the human condition" (Holbrook, 2005, p. 45).

Levy (1996) also uses introspection to reflect on his interest in marketing and consumer research particularly his love for food and the involvement of food companies in marketing research. He reflects on societal obsession with seeking ways to harness life, the case of consumers' extreme health conscious behaviours and the quandary they faced when deciding between monitoring their food consumption and indulging in the pleasure of eating out. He concluded that eating should be done in exotic gourmet locations and what he refers to as a 'consumer amphisbaena' would eat out and choose delicious food. He also questioned how researchers could capture consumption in an insightful way attributing the growth of qualitative methods to the researcher's desire to understand consumer motivations and actions. Hence, introspection has become an inevitable aspect of consumer research used in the study of aesthesis and inner lives of people.

Wohlfeil \& Whelan (2012) also uses SPI to showcase Wohlfeil's fan love and adoration of the film actress Jena Malone from her role in the film 'saved' showing how one movie introspection allowed the exploration of the subjective nature of human feelings, a method of getting emotional experience that is inaccessible by other research methods. Wohlfeil applied a narrative form of SPI where the researcher narrates a story, mostly their own story tagged 'an extreme form of participant observation'. From his introspective account, it was illustrated that prior to his immersion in the film actress, he experienced loneliness which was filled with his fandom activities. He also uses the narrative transportation approach to describe how being a loyal fan allows him to escape his lonely feeling. Essentially, his introspective account was a superb tool for establishing perspective on external culture and self (Gould, 2008).

In subsequent years, the inception of the Consumer Introspective Theory (CIT) by Gould (2012), advocated the use of introspective methods to reveal the experiential aspects of consumption. The credibility of this research method can be ascertained by its true subjective exploration to evaluate experiential aspect of consumption, credibility of the researcher and its philosophical value in utilizing qualitative inquiry to understand human 
condition (Patton, 2002). Hence, reliability and validity is derived from the narrators credibility to narrate the real experience that makes the account a true representation of what was experienced (Ellis et al., 2011). Experiences were collected as raw contemporaneous data from written words as expressed in the film to ensure high data accuracy which also provides a pool of emotional data on feelings and thoughts (Wohlfeil and Whelan, 2008, 2011, 2012).

\subsection{Learning about eat, pray, love}

The lead author was informed about the film 'Eat, Pray, Love' from a friend in 2017 who enthusiastically recommended that she watched it. The film was chosen for this analyses because introspecting on this film the context and meaning were sufficient to draw lessons from (Gould, 2012). Eat pray love was originally recorded as a book, a real life story where the author narrated her real life experience, alternating some names in the book to ensure anonymity. Although, this research has chosen to introspect on the film instead because films represent the visual that is more effective than mental images depicted in the book. McGinn (2004) illustrates the impact of mental and visual image while the mental image of the book might leave the reader second guessing the actual perceptual image, the film presents the visual details visible to the eye something present and real. Thus the film's visual goes beyond the mental. Additionally, Martin (2005) illustrated how films over other methods reveals the visual representation of food. The title of the film Eat, Pray, Love seems to be one of the easiest descriptions, representing three words, three feelings, it is very glaring that the film drives towards three emotions (Fredrickson, 2001); the emotions of eating- that is food consumption, where this could involve the simple, complex, fancy foods or even drink; praying, an act added to this film that signifies that there would be a religious aspect to this although, the word pray has been used generally by people in the world to denote anything from 'pray it may happen' to let's hope and pray' without practising or implementing their word by praying. Hence, it was interesting to see how this would play out in a film. Lastly, the word 'love' signifying affection, romantic nature whose element is now included in most films to the point of being considered a cliché.

However, what was most striking was the order that these three words were arranged with the word eat first. It was then questioned if eating was most important among the other two, if the nourishment of the body was primary before praying or loving. Perhaps, it draws the attention of the reader to recognise the importance of eating which is sometimes neglected or played down by the situational aspects such as busy schedules and ultimately no time. Thus, we sometimes forget the importance of eating. Considering the bearing of this research, the lead author introspects exclusively on the 'Eat' aspect. Hence, the following section represents the lead author's introspective account of this film and interpretation.

\subsection{Introspecting on Eat, Pray, Love}

Introspecting on this film, I can perceive certain aspects of Liz's life in mine. This film takes me back to a dark point in my life where I, like the lead actress 'Liz', had just experienced a major disappointment in my life. At that point I had experienced failure after failure and had reached the mentality where I felt like no matter how hard I tried it was not going to work. I was like a walking corpse tracing my own shadow while uncertain of the being that embodied 
that shadow. To use the term 'disappointment' now seems like an understatement but I felt like my very own ego had split before my eyes. This helpless state translates to the scenario of Liz's emptiness and soul searching where Liz exclaimed that she had reached "infatuations final destination, the complete and merciless devaluation of self". To me, this fitted closely to my state then, when I felt like a helpless and demoralized being. To preserve my mental health, I would not try to narrate the details of the circumstances that led to the disappointment I felt, but the process I took to overcome it. A period that led to certain pleasurable experiences with food that affected my subjective wellbeing.

This state of devalued self, made me ultimately withdrawn. My weakened mind and body which would have driven me to consume food instead inhibited my food consumption. Anytime I attempted to eat meals I previously enjoyed, I felt this urge to reject it. I convinced myself that I was full or perhaps I was not hungry. Other times, I forced myself to eat, I would later vomit the food I had ingested. It was at this moment I questioned myself if I had lost the taste of food, if my tongue had lost the means to savour. However, I was losing strength and decided I needed to make a change. Glancing through YouTube one day, I came across a discussion on superfoods and how they helped to revitalize the mind and body. That was where it started, I consoled myself by acting as a healthy food activist. I attempted to consume such foods and now embodied a positive attitude towards healthy food (Batat et al., 2017). My healthy food obsession was spirulina, pumpkin and linseed seeds. I initially bought these food products only online but I later found them in my local grocery store which became easily accessible. I bought packs of spirulina powder, pumpkin seeds and consumed them daily, while I would brace myself that its taste was fine after all, its healthy food and health meant wealth. I was able to convince myself that I was doing the right thing and that consuming a healthy food will make me survive the pain that was avoiding. Unconsciously, I had undergone the three stages of adopting the 'alternative food consumption' (APC) pattern where I had first attempted to control my food consumption through analyzing objective factors in this case my loss of enthusiasm of tasting food; with me reflecting on the individual relationship with food I previously had, to the stage where I questioned established norms on food (Batat et al., 2016, 2017). Moreover, consuming the spirulina diet, I became a snob and exhibited a 'bourgeois-bohemians' behavior were I felt consuming this new diet made me eccentric (Batat et al., 2016). Although this kept me going for a while it was short-lived.

Unlike Liz, I did not have the luxury to just abandon my life and escape to a different country. I was performing a specific project that I had to finish at that time. However, towards the end of the project, I felt I just wanted to leave that place. Just like Liz exclaimed when she said, "I used to have this appetite for food, for my life and it is just gone... I want to go someplace I can just marvel at something, languages, gelatos, spaghetti, something" Moreover, as represented in Bryant and Veroff (2007), it was mine as well as Liz's search for love and social responsibility that inhibited us from savouring food. Towards the next stage of my life I moved to a different city, a smaller one compared to the one I was previously in. There was no noise and I was suddenly filled with a certain tranquility that overwhelmed my body. This gave me time for sober reflection, when I began to perceive my selfworth and love myself again. My eyes began to open to certain things that I may have been previously oblivious to or perhaps began to appreciate from the characteristics of people around me. 
In my new city, I was living in a flat encompassed of a multinational community. Watching this film made me reflect on a similar occurrence between two of my flat mates. Particularly, the scene where Liz's friend did not want to indulge in pleasurable eating due to concerns of her weight. In my scenario, the girl exclaimed why see needed to lose weight and how her friends and family will consider her fat. She also began her journey towards the healthy living by jogging almost daily and consuming meals consisting of salmon. Then the guy asked her where the fat in her body was, expressed that she was worrying about nothing and should eat. Truly in my eyes she was not fat but then again neither was I. Yet, I was consuming spirulina and trying to convince myself that my body can be liberated through consuming healthy food. While that seemed intriguing to me, at that point I started questioning my existing food values.

This became the turning point of my life and I began to experience food in a different light. Besides, food experience deals with the reason and pattern of how people eat and not necessarily what is eaten (Batat et al., 2017). Although I was drinking Spirulina, which I somewhat felt was giving me power, I still felt I was lacking something and was not experiencing food in its fullness. I went to the local grocery store and bought ingredients of the local cuisines and cooked them. I did not just cook them I paid attention to the seasoning, the taste and texture. It was at this point I was also, lost in social media were I would be daily flooded with timeless images of food that watered my mouth. People's display of food on social media particularly Instagram was synonymous to food porn representing the visual aesthetic of lingering food (McDonnell, 2016), a pattern of digital photo sharing (De Choudhury et al., 2016; Kozinets et al., 2017). This was also, similar to the way Liz viewed the meals presented in a similar artistic manner. Hence, after my cooking I did not just dish it up in a plate, I did what the chefs call 'I plated the food' an artistic visual representation of food. I made sure the meal looked colourful to the onlooker's eyes in a way that will entice their taste buds. I transitioned to enjoy food again in a different location as Liz did when she exclaimed 'I am having a relationship with my pizza'. I too began to have a relationship with my home cooking. Unlike Liz, who took pleasure mostly by enjoying gastronomical cuisines outdoors I enjoyed eating my homemade meals. However, I exhibited experiential aspects that further triggered novelty, tasting, aesthesis that led me to adopt a different pattern of alternative food consumption (Batat et al., 2017). With every bite of the food, I would tap myself on the back and just savour the goodness that my own hands have created. This became a routine, a hobby were I would occasionally cook for friends so they too can taste and savour the magic that I create. This savouring experience was witnessed as I appreciated the taste of food (Bryant and Veroff, 2007) and it was this pleasurable experience with food that led to my happiness.

\section{Discussion and Conclusion}

The contribution of this paper is it illustrates the pleasurable experiences associated with food that contributes to a consumer's subjective wellbeing. Predominately, it traces the experiential stages of consuming food pleasure from a loss of self, to consuming alternative foods towards consuming wellbeing and happiness. This results in emerging themes of epicurean ingestion which can be remodeled to marketing actions. Just like Batat et al. (2017) recommended cooking experiential classes for students, experiential classes should be marketed to people who have experienced emptiness or are soul searching, this would move people towards experiencing such pleasures from 
food. Importantly, it contributes to the alternative food consumption framework which emerged from TCR to consider the reaction of the perceived failure of a dominant food consumption pattern following concerns of loss of taste (Batat et al., 2016). Furthermore, alternative food are now available in most grocery stores at affordable prices so the next stage should be directed towards advertising pleasures of food that are made at home.

This paper also contributes to the APC framework that accounts for the allocentric and idiocentric factors that led to alternative food consumption (Batat et al., 2017). In the first instance the lead author's situational factors are attributed to the consumption of organic food. Hence, situational factors is a major driver of AFC. Although, it may be viewed as a deviation from the initial superfood consumption, the subsequent consumption of slow food through home cooking exhibits ideological consumption. This change was as a result of the societal values transferred to the lead author, adapted into alternatives which became part of her sociocultural structure (Batat et al., 2016). Also, although income plays a major role in this experiential food consumption it was not a major factor as Liz was willing to forgo her belongings to pursue pleasure from food again and the lead author experimented with different food despite the costs (Batat et al., 2017). This was driven by their desire to express their love for food and drink similar to Aristotle's idea that good life should be pleasurable (Ryff, 1989).

Additionally, although visceral and epicurean eating pleasures were noted (Cornil and Chandon, 2015), this research reveals that they do not exist in isolation. It was the lead author's as well as Liz's negative emotions of emptiness that led to visceral consumption. This is similar to the loneliness described in Wohlfeil and Whelan (2012) before the immersion in the fandom experience. However, there was also the subsequent experience of epicurean eating 'I am having a relationship with my pizza' illustrating that both factors exist as a continuum. Also, this experience of positive effects, less negative effect, are factors reminiscent of SWB (Gruber et al., 2011; Guven and Sørensen, 2012) which also extends to factors that resonates their PWB particularly self-acceptance and personal growth.

Also, the distinction made between hedonia and eudaimonia (Deci and Ryan, 2008) did not apply here. Although they responded to the sensations of eating through hedonic consumption they also experienced eudaimonia. When the lead author and Liz started engaging in the hedonic food consumption, their happiness increased. It can be thought that they reached a state of Eudaimonia - a state of personal expressiveness (Ryan and Deci, 2001). Also, people still consider food wellbeing as a state of eating in moderation or eating healthy food alone as described by Levy (1996), a notion covered by food as health research that dealt with body mass index, restraint and restrictive habits towards food (Block et al., 2011). However, this limits people from enjoying the pleasantries of food. It ignores that people desire emotional, and psychological nourishment from food for comfort, pleasure, love (Block et al., 2011). This behaviour despite thought to improve wellbeing or monitor health instead increased worry and disturbed wellbeing. This shows that food has symbolic significance that affect consumers appreciation of life, their mood, life judgment and social relationships (Ares et al., 2015).

So far, the health industry has particularly focused on the disadvantages of overeating that little effort is accorded to enjoying food (Cornil, 2017), instead the experiential pleasure of eating should be advertised. For instance, this film showcased how food was eaten slowly, appreciating its flavours and sensations in the taste buds rather than the fast binge eating. It will be beneficial if new adverts from health care professionals and food activists 
draws on this aspect of food consumption. Instead of totally preventing people from eating the non-healthy food, they should encourage them to perceive these foods differentially as something to enjoy and appreciate, savouring it in an aesthetic way. This research not only focuses on how people perceive pleasure in food consumption as discussed by Cornil and Chandon (2015) but also illustrates how a film can showcase the experiential aspects of food consumption. It calls other researchers to follow suit in analysing more films to get the emotive aspects and feelings associated with consumption. This paper has considered the introspective reflection of one film but other researchers can analyse other films on experiential aspects of food and other consumption practices ranging from sports to music. They can take it a step further by providing the visual cues expressed by these actors and how they may translate to consume responses to products. This paper has shown the experiential pleasure of food consumption and how this pleasure drives the consumer towards continued consumption. Yet, another research could analyse how and if consumers compare the level of pleasure they can obtain from food products before purchasing them.

In terms of its implication for practice and society, this paper has shown that food wellbeing is not just about the health of the consumer but more about their happiness. It takes a turn on the food well-being and transformative consumer movement to understand that food well-being does not just rely on the limiting factors, that prevent consumers from attaining the healthy status as discussed in Block et al. (2011); Bublitz et al. (2011, 2013) but, their indulgence in eating itself as an act, that is influential to their happiness and wellbeing. Consumers derive happiness from ingesting tasty meals, besides, palatability acts on the hedonic pathways that drives more consumption (Cornil, 2017). For them, wellbeing is not when they continue to follow a strict diet, worrying about their weight but simply by enjoying themselves and eating the food they love. Contrary to this, consumers like Liz, fall into a lonely state that questions her existence and life choices, a state of anxiety which is far from wellbeing. Here, wellbeing is considered a multidimensional construct consisting of both hedonic and eudaimonic elements (Ryan and Deci, 2001). Hence, researchers and food policy makers should understand consumers' appreciation of the pleasures of food and how it benefits them but most importantly, how pleasure is becoming central to consumer food well-being.

\section{References}

Alba, J.W. and Williams, E.F. (2013), "Pleasure Principles: A Review of Research on Hedonic Consumption", Journal of Consumer Psychology, Vol. 23 No. 1, pp. 2-18.

Annas, J. (1987), “Epicurus on Pleasure and Happiness”, Philosophical Topics, Vol. 15 No. 2, pp. 5-21.

Ares, G., de Saldamando, L., Giménez, A., Claret, A., Cunha, L.M., Guerrero, L., de Moura, A.P., et al. (2015), "Consumers' Associations with Wellbeing in a Food-Related Context: A Cross-Cultural Study", Food Quality and Preference, Vol. 40, pp. 304-315.

Batat, W., Manna, V., Ulusoy, E., Peter, P.C., Ulusoy, E., Vicdan, H. and Hong, S. (2016), "New Paths in Researching 'Alternative' Consumption and Well-being in Marketing: Alternative Food Consumption”, Marketing Theory, Vol. 16 No. 4, pp. 561-575.

Batat, W., Peter, P.C., Vicdan, H., Manna, V., Ulusoy, E., Ulusoy, E. and Hong, S. (2017), “Alternative Food Consumption (AFC): Idiocentric and Allocentric Factors of Influence among Low Socio-Economic Status (SES) Consumers", Journal of Marketing Management, Vol. 33 No. 7-8, pp. 580-601. 
Batat, W. and Wohlfeil, M. (2009), "Getting Lost Into the Wild": Understanding Consumers' Movie Enjoyment through a Narrative Transportation Approach", in McGill, A.L. and Shavitt, S. (Eds.), NA - Advances in Consumer Research, Vol. 36, Association for Consumer Research, Duluth, MN, pp. 372-377.

Bauer, J.J., McAdams, D.P. and Pals, J.L. (2008), "Narrative Identity and Eudaimonic Well-Being”, Journal of Happiness Studies, Vol. 9 No. 1, pp. 81-104.

Block, L.G., Grier, S.A., Childers, T.L., Davis, B., Ebert, J.E., Kumanyika, S., Laczniak, R.N., et al. (2011), “From Nutrients to Nurturance: A Conceptual Introduction to Food Well-Being", Journal of Public Policy \& Marketing, Vol. 30 No. 1, pp. 5-13.

Bourdieu, P. (1984), Distinction: A Social Critique of the Judgement of Taste, Harvard University Press, Cambridge, Massachusetts.

Brown, K.W. and Ryan, R.M. (2003), "The Benefits of Being Present: Mindfulness and its Role in Psychological Well-Being”, Journal of Personality and Social Psychology, Vol. 84 No. 4, pp. 822-848.

Bruni, L. (2010), “The Happiness of Sociality. Economics and Eudaimonia: A Necessary Encounter”, Rationality and Society, Vol. 22 No. 4, pp. 383-406.

Bryant, F.B. and Veroff, J. (2007), Savoring: A New Model of Positive Experience, Lawrence Erlbaum Associates, Inc, Mahwah, New Jersey.

Bublitz, M.G., Peracchio, L.A., Andreasen, A.R., Kees, J., Kidwell, B., Gelfand Miller, E., Motley, C.M., et al. (2011), "The Quest for Eating Right: Advancing Food Well-Being", Journal of Research for Consumers, Vol. 19, pp. 1-12.

Bublitz, M.G., Peracchio, L.A., Andreasen, A.R., Kees, J., Kidwell, B., Miller, E.G., Motley, C.M., et al. (2013), "Promoting Positive Change: Advancing the Food Well-Being Paradigm", Journal of Business Research, Vol. 66 No. 8, pp. 1211-1218.

De Choudhury, M., Sharma, S. and Kiciman, E. (2016), "Characterizing Dietary Choices, Nutrition, and Language in Food Deserts via Social Media", Proceedings of the 19th ACM Conference on Computer-Supported Cooperative Work \& Social Computing, Association for Computing Machinery, San Francisco, CA, pp. $1157-1170$.

Cornil, Y. (2017), "Mind Over Stomach: A Review of the Cognitive Drivers of Food Satiation", Journal of the Association for Consumer Research, Vol. 2 No. 4, pp. 419-429.

Cornil, Y. and Chandon, P. (2015), "Pleasure as an Ally of Healthy Eating? Contrasting Visceral and Epicurean Eating Pleasure and their Association with Portion Size Preferences and Wellbeing", Appetite, Vol. 104, pp. $52-59$.

Custer, D. (2014), “Autoethnography as a Transformative Research Method”, The Qualitative Report, Vol. 19 No. 37, pp. 1-13.

Deci, E.L. and Ryan, R.M. (2008), "Hedonia, Eudaimonia, and Well-Being: An Introduction”, Journal of Happiness Studies, Vol. 9 No. 1, pp. 1-11.

Diener, E. (2000), "Subjective Well-Being: The Science of Happiness and a Proposal for a National Index", American Psychologist, Vol. 55 No. 1, pp. 34-43.

Dittmar, H. (2007), Consumer Culture, Identity and Well-Being: The Search for the "Good Life" and the "Body Perfect”, Psychology Press, New York, NY.

Ellis, C., Adams, T.E. and Bochner, A.P. (2011), “Autoethnography: An Overview”, Historical Social Research/Historische Sozialforschung, Vol. 36 No. 4, pp. 273-290.

Fredrickson, B.L. (2001), "The Role of Positive Emotions in Positive Psychology: The Broaden-and-Build Theory of Positive Emotions", American Psychologist, Vol. 56 No. 3, pp. 218-226.

Gorge, H., Özçağlar-Toulouse, N. and Toussaint, S. (2015), "Bien-être and Well-being in Consumer Research: A Comparative Analysis", Recherche et Applications En Marketing, Vol. 30 No. 2, pp. 97-115.

Gould, S.J. (1991), “The Self-Manipulation of My Pervasive, Perceived Vital Energy through Product Use: An 
Introspective-Praxis Perspective", Journal of Consumer Research, Vol. 18 No. 2, pp. 194-207.

Gould, S.J. (2008), “An Introspective Genealogy of my Introspective Genealogy”, Marketing Theory, Vol. 8 No. 4 , pp. $407-424$.

Gould, S.J. (2012), “The Emergence of Consumer Introspection Theory (CIT): Introduction to a JBR Special Issue”, Journal of Business Research, Vol. 65 No. 4, pp. 453-460.

Gruber, J., Mauss, I.B. and Tamir, M. (2011), “A Dark Side of Happiness? How, When, and Why Happiness is not Always Good”, Perspectives on Psychological Science, Vol. 6 No. 3, pp. 222-233.

Guven, C. and Sørensen, B.E. (2012), "Subjective Well-Being: Keeping Up with the Perception of the Joneses", Social Indicators Research, Vol. 109 No. 3, pp. 439-469.

Hirschman, E.C. and Holbrook, M.B. (1982), "Hedonic Consumption: Emerging Concepts, Methods and Propositions", Journal of Marketing, Vol. 46 No. 3, pp. 92-101.

Holbrook, M.B. (1997), "Romanticism, Introspection, and the Roots of Experiential Consumption: Morris the Epicurean”, Consumption Markets \& Culture, Vol. 1 No. 2, pp. 97-163.

Holbrook, M.B. (2005), “Customer Value and Autoethnography: Subjective Personal Introspection and the Meanings of a Photograph Collection”, Journal of Business Research, Vol. 58 No. 1, pp. 45-61.

Holbrook, M.B. (2006), “Consumption Experience, Customer Value, and Subjective Personal Introspection: An Illustrative Photographic Essay”, Journal of Business Research, Vol. 59 No. 6, pp. 714-725.

Holt, B. (1997), "Distinction in America? Recovering Bourdieu's Theory of Tastes from its Critics”, Poetics, Vol. 25 No. 2-3, pp. 93-120.

Hoyer, W.D. and Stokburger-Sauer, N.E. (2012), “The Role of Aesthetic Taste in Consumer Behavior”, Journal of the Academy of Marketing Science, Vol. 40 No. 1, pp. 167-180.

Kalita, K. and Sarma, M.K. (2017), “"Eating out' as Life Style: Yielding to the Impulsive Temptation”, SCMS Journal of Indian Management, Vol. 14 No. 4, pp. 76-94.

Kaza, S. (2008), Mindfully Green: A Personal and Spiritual Guide to Whole Earth Thinking, Shambhala Publications, Boston, Massachusetts.

Kozinets, R., Patterson, A. and Ashman, R. (2017), "Networks of Desire: How Technology Increases our Passion to Consume”, Journal of Consumer Research, Vol. 43 No. 5, pp. 659-682.

Kronrod, A., Grinstein, A. and Wathieu, L. (2012), "Enjoy! Hedonic Consumption and Compliance with Assertive Messages”, Journal of Consumer Research, Vol. 39 No. 1, pp. 51-61.

Lee, M.S. and Ahn., C.S.Y. (2016), “Anti-Consumption, Materialism, and Consumer Well-being”, Journal of Consumer Affairs, Vol. 50 No. 1, pp. 18-47.

Levy, S.J. (1996), “Stalking the Amphisbaena”, Journal of Consumer Research, Vol. 23 No. 3, pp. $163-176$.

Lyubomksky, S., Sheldon, K.M. and Schkade, D. (2005), "Pursuing Happiness: The Architecture of Sustainable Change", Review of General Psychology, Vol. 9 No. 2, pp. 111-131.

Madichie, N.O. (2007), "Nigerian Restaurants in London: Bridging the Experiential Perception/Expectation gap", International Journal of Business and Globalisation, Vol. 1 No. 2, pp. 258-271.

Maret, O.D. and Geyzen, A. (2015), “Tastes of Homes: Exploring Food and Place in Twentieth Century Europe”, Food and Foodways, Vol. 23 No. 1-2, pp. 1-13.

Martin, E. (2005), "Food, Literature, Art, and the Demise of Dualistic Thought", Consumption Markets \& Culture, Vol. 8 No. 1, pp. 27-48.

McDonnell, E.M. (2016), "Food Porn: The Conspicuous Consumption of Food in the Age of Digital Reproduction", in Bradley, P. (Ed.), Food, Media and Contemporary Culture: The Edible Image, Palgrave Macmillan, London, pp. 239-265.

McGinn, C. (2004), Mindsight, Harvard University Press, Cambridge, Massachusetts. 
Mick, D.G. (2006), "Presidential Address: Meaning and Mattering Through Transformative Consumer Research", in Pechmann, C. and Price, L. (Eds.), NA - Advances in Consumer Research, Vol. 33, Association for Consumer Research, Duluth, MN, pp. 1-4.

O'Keefe, T. (2014), Epicureanism, Routledge, Abingdon, Oxon.

Ozanne, J.L. (2011), "Introduction to the Special Issue on Transformative Consumer Research: Creating Dialogical Spaces for Policy and Action Research", Journal of Public Policy \& Marketing, Vol. 30 No. 1, pp. 1-4.

Patton, M.Q. (2002), Qualitative Evaluation and Research Methods, 3rd ed., Sage, London.

Rezende, D.C.D. and Silva, M.A.R. (2014), "Eating-out and Experiential Consumption: a Typology of Experience Providers", British Food Journal, Vol. 116 No. 1, pp. 91-103.

Ryan, R.M. and Deci, E.L. (2001), "On Happiness and Human Potentials: A Review of Research on Hedonic and Eudaimonic Well-Being”, Annual Review of Psychology, Vol. 52 No. 1, pp. 141-166.

Ryan, R.M., Huta, V. and Deci, E.L. (2008), “Living Well: A Self-Determination Theory Perspective on Eudaimonia”, Journal of Happiness Studies, Vol. 9 No. 1, pp. 139-170.

Ryff, C.D. (1989), "Happiness is Everything, or is it? Explorations on the Meaning of Psychological Well-Being", Journal of Personality and Social Psychology, Vol. 57 No. 6, pp. 1069-1081.

Ryff, C.D. and Singer, B.H. (2008), "Know Thyself and Become What You Are: A Eudaimonic Approach to Psychological Well-Being", Journal of Happiness Studies, Vol. 9 No. 1, pp. 13-39.

Spence, C. (2017), “Comfort Food: A Review”, International Journal of Gastronomy and Food Science, Vol. 9, pp. $105-109$.

Titz, K. (2008), "Experiential consumption: Affect - Emotions - Hedonism”, in Oh, H. and Pizam, A. (Eds.), Handbook of Hospitality Marketing Management, Elsevier, Oxford, pp. 324-352.

Wansink, B., Cheney, M.M. and Chan, N. (2003), "Exploring Comfort Food Preferences across Age and Gender", Physiology and Behavior, Vol. 79 No. 4-5, pp. 739-747.

Waterman, A.S. (1993), "Two Conceptions of Happiness: Contrasts of Personal Expressiveness (Eudaimonia) and Hedonic Enjoyment", Journal of Personality and Social Psychology, Vol. 64 No. 4, pp. 678-691.

Wohlfeil, M. and Whelan, S. (2008), "Confessions of a Movie-Fan: Introspection into a Consumer's Experiential Consumption of 'Pride and Prejudice"”, in Borghini, S., McGrath, M.A. and Otnes, C. (Eds.), E - European Advances in Consumer Research, Vol. 8, Association for Consumer Research, Duluth, MN, pp. 137-143.

Wohlfeil, M. and Whelan, S. (2011), "The Book of Stars": Understanding a Consumer's Fan Relationship With a Film Actress Through a Narrative Transportation Approach", in Bradshaw, A., Hackley, C. and Maclaran, P. (Eds.), E - European Advances in Consumer Research, Vol. 9, Association for Consumer Research, Duluth, MN, pp. 290-296.

Wohlfeil, M. and Whelan, S. (2012), “'Saved!' by Jena Malone: An Introspective Study of a Consumer's Fan Relationship with a Film Actress", Journal of Business Research, Vol. 65 No. 4, pp. 511-519.

Zhong, J.Y. and Mitchell, V.W. (2010), "A Mechanism Model of the Effect of Hedonic Product Consumption on Well-Being”, Journal of Consumer Psychology, Vol. 20 No. 2, pp. 152-162.

Zhong, J.Y. and Mitchell, V.W. (2012), “Does Consumer Well-Being Affect Hedonic Consumption?”, Psychology and Marketing, Vol. 29 No. 8, pp. 583-594. 